\title{
$\mathrm{NCDC}$ 데이터를 활용한 냉난방도일 산정 및 계산방법에 관한 연구
}

\section{A Study on Heating and Cooling Degree-Days Calculation Methods with NCDC Data}

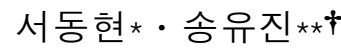 \\ Seo Dong-Hyun* and Song Yujin**†
}

(Submit date : 2013. 11. 4., Judgement date : 2013. 11. 5., Publication decide date : 2013. 12. 20.)

\begin{abstract}
Degree-day method is very simple but essential index to estimate heating and cooling energy demand in buildings. It has been neglected, however, for the simplicity so it is difficult to find any DB for south Korean cities. Even meteorological department of S. Korea doesn't report the data officially.

In this study, current methods that are being used in many countries are investigated and used to calculate degree-days of 35 south Korean cities with 30 years (1981 2010) historical data. The calculation result indicates that the error among 4 major methods are dependent on how daily or hourly temperature are treated in the calculation and how balance point temperature is defined. The errors of the methods are no larger than $6 \%$ relative to hourly degree-day method.
\end{abstract}

Key Words : 도일 (degreee-days), NCDC(National Climatic Data Center), 평형점온도 (Balance point temperature)

\section{1. 서 론}

\section{1 연구의 목적}

건물 에너지사용량의 예측 및 관리는 과거 부터 지금까지 그 중요성이 간과된 적이 없으
나, 최근 지구온난화의 심화, 화석연료의 고갈 에 대한 우려, 신재생에너지원의 개발 및 적 용, 스마트그리드와 같은 전통적인 에너지 공 급방식의 급격한 변혁을 앞두고 있는 상황에 서 그 중요성이 더해가고 있다.
* 서동현: 충북대학교 건축공학과 교수

**† 송유진(교신저자): 한국에너지기술연구원 책임연구원

E-mail : eugene@kier.re.kr, Tel : 042-860-3120
*Seo Dong-hyun: Department of Architectural Engineering, Chungbuk National University, Assistant Professor **† Song Yujin(corresponding author): Korea Institute of Energy Research, Principal researcher

E-mail: eugene@kier.re.kr, Tel : 042-860-3120 
이러한 에너지기술의 대전환기에 있어서 오 래된 이론이자 가장 단순한 건물에너지 예측 기법 중 하나인 도일법은 오히려 그 단순함이 란 특성으로 여전히 건물에너지에 관한 유효 한 정보를 제공할 수 있다. 예를 들어, 난방기 의 성능이 외기온도에 상관없이 일정하다는 전제를 한다면 난방에너지 사용이 여전히 주 요한 에너지소비원인 주거용 건물에서 이 기 법은 간단하면서도 정확하게 에너지 사용량을 추정할 수 있다. 이러한 장점으로 인해 도일법의 개선된 방법인 빈법(bin method), 국내 공동 주택의 에너지효율등급을 계산하는 프로그램에 활용되고 있으며, 상업용 건물의 에너지사용 량을 예측하는 ECO-2 프로그램에서도 직접 적이지는 않지만 부분적으로 활용되고 있다.

이러한 상황에도 불구하고, 국내에서는 공식 적인 냉난방도일을 계산하는 방법이나 결과데이 터를 도시별로 제공하고 있지 않고 있으며, 오히 려 국외의 $\mathrm{DB}$ 들 속에서 국내 데이터를 참고해 야 하는 상황이다. 본 연구에서는 미(美) 기상청 산하 $\mathrm{NCDC}$ 를 통해 얻을 수 있는 국내도시의 기 상데이터를 수집하고, 문헌고찰을 통해 냉난방 도일을 계산하는 방법들을 알아보며, 각 방법들 의 결과를 상호 비교분석한 후 이를 통하여 국내 주요도시들의 냉난방도일을 제시하고자 한다.

\section{2 연구의 방법 및 절차}

본 연구에서는 미국의 기상청(NOAA) 산하 NCDC (National Climatic Data Center)의 데 이터를 주요 소스데이터로 활용하였으며 국내 기상청으로부터 입수한 데이터를 검증자료로 활용하였다. NCDC로부터 과거 30년간 (1981 2010년)의 데이터를 국내 87개 도시를 대상 으로 입수하였으며 수집 데이터의 QC(quality control)를 통해 35 개소로 1차 분석대상을 한 정하였다. 선택된 개소의 $\mathrm{NCDC}$ 데이터는 3 시
간 단위로 작성되어 있기 때문에 매시간 데이 터로 변환하기 위한 보간법을 필요로 하며 보 간법의 성능을 검증하기 위해 국내 기상청으 로부터 입수한 매시각별 데이터를 활용하였 다. 매시각데이터로 변환된 $\mathrm{NCDC}$ 데이터와 냉난방도일 계산방법에 대한 문헌고찰을 통하 여 확인된 계산법을 활용하여 선정된 국내 도 시에 대한 냉난방도일을 계산하고 그 결과를 비교하여 계산방식별 결과의 오차율을 제시하 였다. 마지막으로, 결과분석을 통해 오차를 가 져오는 원인을 분석하였으며, 이를 통해 계산 방식별 발생오차의 근원을 파악하여 앞으로 유사한 연구에 참고할 수 있도록 하였다.

\section{2. 국내외 문헌고찰}

국내의 건물에너지를 위한 냉난방도일법에 관한 연구는 미약하지만 지속적으로 진행되어 오고 있으나 최근 들어서는 냉난방도일법을 이용한 장기간의 기후변화 (박명희 외, $2004^{1)}$; 김지혜 외, $2006^{2)}$ ) 및 건물의 에너지사용량 기 준을 설정하기 위한 연구 (최상호 외, 20133) 가 주를 이루고 있다. 이들은 장기간의 기온변 화를 쉽게 나타내주는 지표로서 냉난방도일을 활용하여 1) 도시 및 근교에 있는 기상관측소 에서 측정한 외기온의 장기온도변화의 추이를 예측하거나 2) 이에 따른 에너지사용량 및 탄 소배출량을 예측하는 방법을 제시하고 있으 며, 3) 장기 에너지사용량 변화를 고려한 단열 기준이나 기준건물(baseline building)의 에너 지사용량을 제시하는 방법을 제안하였다. 특 히, 최영은 $(2005)^{4)}$ 의 연구에서는 도시와 교외 지역의 냉난방도일 변화추이 분석을 통해 최 근의 일부 도시들의 냉방도일 증가와 난방도 일 감소추세는 지구 온난화보다는 도시화에 따른 영향이 훨씬 크다는 것을 밝혀내기도 했다. 
한편 조성환 등 $(2008)^{5)}$ 은 가장 기본적인 냉 난방도일 계산수식 (1)과 (2)의 $\theta_{b}$, (실내설정 온도 또는 평형점온도: balance point or base temperature)를 사용하여 실외온도와 실설정 온도 및 실설정온도와 평형점온도(설비공학 편람 (2011)에 따르면 총 열손실이 태양열 복 사, 재실자, 조명 등에 의한 열취득과 같아지는 외기온도)의 차이가 존재할 경우 이를 난방도 일 계산에 반영하였다. 예를 들어, 난방도일의 계산에서 일평균 외기온도가 실설정온도보다 작을 경우에만 그 날의 두 온도간의 차이값을 누적하는 방식에 추가적으로 실설정온도와 평 형점온도의 차이까지 추가하는 방식으로 국내 15 개 도시에 대한 평형점 온도별 난방도일값 을 1971 년부터 2006년까지의 37년의 데이터를 사용하여 계산하였다. 유사한 연구로 이혜린 등(2011)의 연구결과를 볼 수 있는데, 이들은 도시온난화의 영향을 고려한 냉난방도일계산 방법을 제안하기 위하여 1981년부터 2010년 30 년간의 기상데이터를 이용하여 국내 19 개 도시의 냉난방도일을 계산하였으며 이때 사용 한 수식은 기본적으로 수식 (1) 및 (2)와 같다. 이들은 최근 10 년의 데이터에 더 큰 가중치를 임의로 부여하는 방법을 통해 10년 단위로 가 중치가 부여된 냉난방도일을 계산하였으며 그 값의 차이는 $1 \%$ 내외로 보고되었다.

국외의 냉난방도일에 관한 연구의 경우 Mourshed $(2012)^{6}$ 가 월평균외기온과 월별 표 준편차를 이용하는 방법을 중심으로 다양한 도일법 수식들을 이용하여 계산결과를 비교하 였으며, 영국의 CIBSE (Chartered Institution of Building Services Engineers)에서 발행한 보고서 $(2006)^{7)}$ 에서도 이러한 방법들을 체계적 으로 정리하여 제시하고 있다. 이 보고서에 따 르면 냉난방도일 계산법은 크게 4 가지로 구분할 수 있는데 수식 (3)과 (4)는 mean degree-hours method (Method 1)라 부르며 수식 (5)와 (6) 은 영국에서 공식적으로 사용하는 수식이며, 미국은 이 수식의 단순화 버전을 사용한다. 수 식 (1) (6)과 그 특징은 Table 3과 같다.

$$
\begin{aligned}
& H_{d}=\sum_{i=1}^{N}\left(\theta_{b}-\theta_{o}\right)^{+} \\
& C_{d}=\sum_{i=1}^{N}\left(\theta_{o}-\theta_{b}\right)^{+}
\end{aligned}
$$

여기서,

$H_{d}, C_{d}$ : Heating/Cooling Degree-Day

$\left[{ }^{\circ} \mathrm{C}\right.$-day $]$

$\theta_{b}$ : Balance point temperature (평형점온도) $\theta_{o}$ : 일평균 외기온도 $\left[{ }^{\circ} \mathrm{C}\right]$

$$
\begin{aligned}
H_{d} & =\frac{\sum_{j=1}^{24}\left(\theta_{b}-\theta_{o, j}\right)}{24}\left(\left(\theta_{b}-\theta_{o, j}\right)>0\right) \\
C_{d} & =\frac{\sum_{j=1}^{24}\left(\theta_{o, j}-\theta_{b}\right)}{24}\left(\left(\theta_{o, j}-\theta_{b}\right)>0\right)
\end{aligned}
$$

여기서,

$\theta_{o, j}:$ 매시각별 외기온도 $\left[{ }^{\circ} \mathrm{C}\right]$

$$
\begin{gathered}
H_{d}=\sum_{n=1}^{n}\left(\theta_{b}-\theta_{o, a v g}\right),\left(\theta_{b}-\theta_{o, a v g}\right)>0 \\
C_{d}=\sum_{n=1}^{n}\left(\theta_{o, a v g}-\theta_{b}\right),\left(\theta_{o, a v g}-\theta_{b}\right)>0
\end{gathered}
$$

여기서,

$\theta_{o, a v g}:$ Table 1 및 Table 2에서 제시한 상황 에 따라 계산된 일평균 외기온 $\left[{ }^{\circ} \mathrm{C}\right]$

식 (5)와 (6)을 위해선 약간의 설명이 필요 한데, Fig 1을 보면 우리가 어떤 온도를 해당 건물의 평형점 온도로 결정하든 그림과 같은 네 
가지 일별 온도변화의 다른 유형이 나타나게 된 다. 영국의 경우 이러한 온도변화와 평형점온도 의 관계를 고려하여 냉난방도일을 계산하는 방법 을 개발하였는데 이것을 Meteorological Office equations 이라하며 본 연구의 계산방법 2 (Method 2)에 해당한다. Table 1과 2는 Fig. 1에 해당하는 네 가지의 경우 계산식을 보여준다.

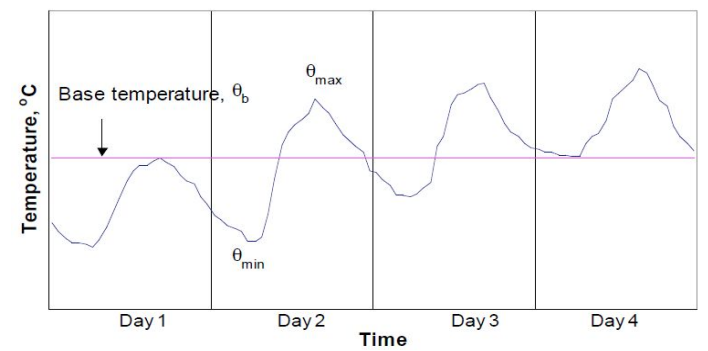

Fig. 1 Four days of outdoor temperature that have different relative variations about the base temperature [CIBSE, 2006]

Table. 1 'Meteorological Office' equations for calculating daily heating degree-days

\begin{tabular}{c|l|l}
\hline Case & Condition & $\begin{array}{l}\text { Daily heating } \\
\text { degree-day }\end{array}$ \\
\hline $\mathrm{A}$ & $\theta_{\max } \leq \theta_{b}$ & $\theta_{b}-1 / 2\left(\theta_{\max }+\theta_{\min }\right)$ \\
\hline $\mathrm{B}$ & $\begin{array}{l}\theta_{\mathrm{m} \text { in }}<\theta_{b} ; \text { and } \\
\left(\theta_{\mathrm{max}}-\theta_{b}\right) \leq\left(\theta_{b}-\theta_{\mathrm{m} \text { in }}\right)\end{array}$ & $\begin{array}{l}1 / 2\left(\theta_{b}-\theta_{\mathrm{m} \text { in }}\right)-1 / 4 \\
\left(\theta_{\mathrm{max}}-\theta_{b}\right)\end{array}$ \\
\hline $\mathrm{C}$ & $\begin{array}{l}\theta_{\max }>\theta_{b} ; \text { and } \\
\left(\theta_{\max }-\theta_{b}\right)>\left(\theta_{b}-\theta_{\min }\right)\end{array}$ & $1 / 4\left(\theta_{b}-\theta_{\mathrm{min}}\right)$ \\
\hline $\mathrm{D}$ & $\theta_{\min } \geq \theta_{b}$ & 0 \\
\hline
\end{tabular}

Table. 2 'Meteorological Office' equations for calculating daily cooling degree-days

\begin{tabular}{c|l|l}
\hline Case & Condition & $\begin{array}{l}\text { Daily cooling } \\
\text { degree-day }\end{array}$ \\
\hline $\mathrm{A}$ & $\theta_{\min } \geq \theta_{b}$ & $1 / 2\left(\theta_{\max }+\theta_{\min }\right)-\theta_{b}$ \\
\hline $\mathrm{B}$ & $\begin{array}{l}\theta_{\mathrm{max}}>\theta_{b} ; \text { and } \\
\left(\theta_{\mathrm{max}}-\theta_{b}\right) \geq\left(\theta_{b}-\theta_{\mathrm{m} \text { in }}\right)\end{array}$ & $\begin{array}{l}1 / 2\left(\theta_{\mathrm{max}}-\right. \\
\left.\theta_{b}\right)-1 / 4\left(\theta_{b}-\theta_{\mathrm{m} \text { in }}\right)\end{array}$ \\
\hline $\mathrm{C}$ & $\begin{array}{l}\theta_{\min }<\theta_{b} ; \text { and } \\
\left(\theta_{\max }-\theta_{b}\right)<\left(\theta_{b}-\theta_{\min }\right)\end{array}$ & $1 / 4\left(\theta_{\mathrm{max}}-\theta_{b}\right)$ \\
\hline $\mathrm{D}$ & $\theta_{\max } \leq \theta_{b}$ & 0 \\
\hline
\end{tabular}

Table. 3 Features of the selected degree-days calculation methods

\begin{tabular}{c|l|l}
\hline Method & Equation & Remark \\
\hline 1 & Eq (3) \& (4) & $\begin{array}{l}\text { The most precise method } \\
\text { mathematically. Need hourly } \\
\text { temperature data }\end{array}$ \\
\hline 2 & $\begin{array}{l}\text { Eq (5), (6) \& } \\
\text { CIBSE Criteria }\end{array}$ & $\begin{array}{l}\text { Official method of the UK } \\
\text { Need complex calculation }\end{array}$ \\
\hline 3 & $\begin{array}{l}\text { Eq (5), (6) \& } \\
\text { CIBSE Criteria }\end{array}$ & $\begin{array}{l}\text { Official method of the USA } \\
\text { \& Germany } \\
\text { Useful if temporal resolution } \\
\text { of measured data is high }\end{array}$ \\
\hline 4 & Eq (1) \& (2) & Usually used in the ROK \\
\hline
\end{tabular}

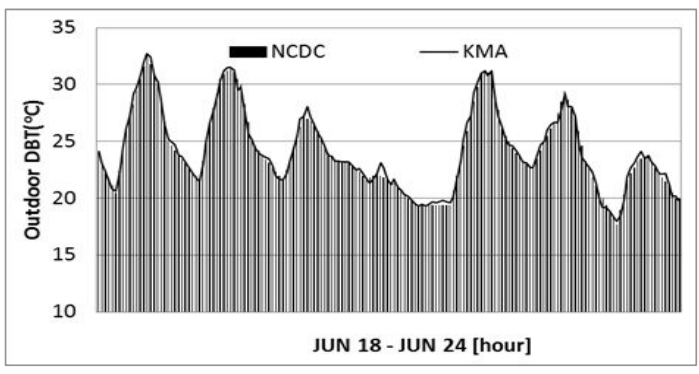

a. Seoul

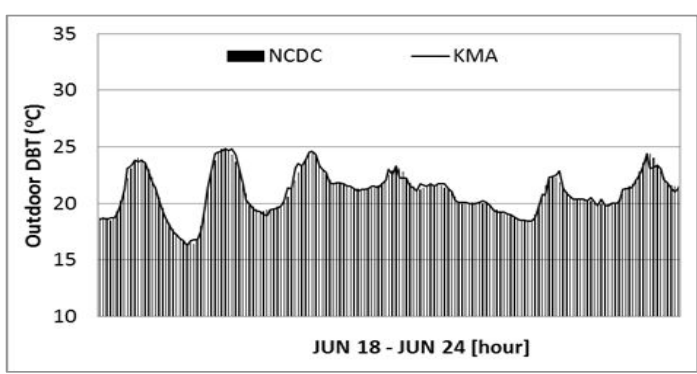

b. Busan

Fig. 2 Comparison of hourly DBT of KMA and interpolated NCDC data

냉난방도일 계산방법 3 (Method 3)은 미국 (ASHRAE, 2001)과 독일 (German Standard VDI 2067)에서 공식적으로 사용하고 있는 계 산방식으로 위의 계산방식 2의 각 Case A에 해당할 경우는 영국과 같은 방식을 사용하나 
Case B에 해당할 경우에도 Case A수식을 사 용하는 것이 특징이다. 즉 영국과 같이 복잡한 케이스를 고려하지 않고 단순히 그 날의 최대, 최소 온도의 평균값과 기준온도와의 차이로 냉난방도일을 계산하는 방식이다. CIBSE에서 언급되지는 않았지만 수식(1)과 (2)가 국내에 서 사용되는 방식이므로 본 연구에서는 이 방 식은 계산방식 4 (Method 4)로 추가하여 각 방식의 계산특성을 비교분석 하였다.

\section{3. 기상자료 수집 및 분석}

\section{$3.1 \mathrm{NCDC}$ 데이터의 수집 및 처리}

$\mathrm{NCDC}$ 는 각 국의 기상청데이터를 국제협 약에 의하여 수집 및 가공하여 약 3500 개소의 기상데이터를 제공하고 있는데 전 세계적인 수요자들을 대상으로 표준화된 $\mathrm{DB}$ 로 공급하기 위하여 매 3시간별 데이터를 UTC (Universal Time Coordinate) 시스템을 기준으로 저장하고 있다. 따라서 표준시간 변경과 매시각별 데이터 로 변환하기 위한 보간법 등의 사전처리가 필요 하게 된다. 하루 중 온도는 급격하게 변하지 않 고 보간간격이 넓지 않기 때문에 선형보간법만 으로도 매시각별 오차의 절대값 평균이 $2.0 \%$ 이하로 충분한 정확도를 가지고 있음을 Fig 2는 보여주고 있다. Fig 2는 2010년 하지를 중심으 로 1 주일간 서울과 부산의 기상청 측정값과 $\mathrm{NCDC}$ 의 3시간별 데이터를 매시각별 데이터로 보간하여 비교한 결과를 보여주고 있다.

\section{4. 냉난방도일의 계산 및 비교}

\section{$4.1 \mathrm{NCDC}$ 데이터의 활용성 검증}

3 시간 간격 $\mathrm{NCDC}$ 데이터를 보간법을 통해 생산한 매시각별 데이터가 큰 오차없이 국내의 공식 기상청 데이터를 대신하여 활용가능한지
를 도일계산 결과의 측면에서 검토하였다. 앞 서 매시각별 온도의 절대오차는 최대 $2.0 \%$ 이 내였으며, Table 4에서 보는 바와 같이 2001년 부터 2010년까지 10년간 공식 기상청 데이터를 이용하여 서울과 부산의 $\mathrm{HDD}$ 및 $\mathrm{CDD}$ 를 계 산한 결과와 비교하여 $\mathrm{HDD}$ 의 경우 최대 $0.71 \%$ 의 절대오차를, $\mathrm{CDD}$ 의 경우 $\mathrm{HDD}$ 값에 비해 그 값이 작기 때문에 상대적으로 높은 최대 $3.29 \%$ 의 절대오차를 보이고 있다. 하지만, 대 부분의 경우 $1.0 \%$ 이내의 오차를 보이고 있 어 보간법을 사용한 $\mathrm{NCDC}$ 데이터를 도일계산 에 활용하여도 큰 무리가 없음을 알 수 있다.

Table. 4 DD Calculation error of interpolated NCDC data relative to $\mathrm{KMA}$ data

\begin{tabular}{c|c|c|c}
\hline Method & Degree Day & Seoul & Busan \\
\hline \multirow{2}{*}{ Method 1 } & HDD & $0.04 \%$ & $0.17 \%$ \\
\cline { 2 - 4 } & CDD & $1.12 \%$ & $1.57 \%$ \\
\hline \multirow{2}{*}{ Method 2 } & HDD & $0.20 \%$ & $0.48 \%$ \\
\cline { 2 - 4 } & CDD & $1.81 \%$ & $3.29 \%$ \\
\hline \multirow{2}{*}{ Method 3 } & HDD & $0.16 \%$ & $0.71 \%$ \\
\cline { 2 - 4 } & CDD & $0.96 \%$ & $2.23 \%$ \\
\hline \multirow{2}{*}{ Method 4 } & HDD & $0.27 \%$ & $0.42 \%$ \\
\cline { 2 - 4 } & CDD & $0.34 \%$ & $0.74 \%$ \\
\hline
\end{tabular}

\section{2 각 계산방식의 계산성능 비교}

Fig 3은 Method 1이 수학적인 측면에서난방 도일을 가장 정확하게 계산하므로 다른 방법들 과의 오차가 어느 시점에서 발생하는지를 보여 주고 있다. 하지만 실제 건물에서 재실자나 냉 난방설비의 부하대응성능, 연속 또는 간헐 운전 등 다양한 변동성을 가지고 있기 때문에 특정 계산방법이 건물의 에너지사용량 예측의 측면 에서 우월하다고 할 수는 없다. 그러나 Method 1이 매시각별 도일을 고려하므로 가능한 최대 의 도일을 계산하기 때문에, 국내 대부분의 도 시는 다른 방법들의 도일값이 Method 1의 결과 값보다 적다는 것을 이해할 수 있다. 


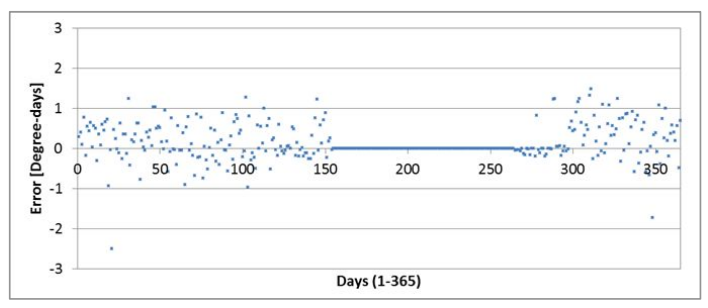

a. DD Error of Method 1 vs. Method 2

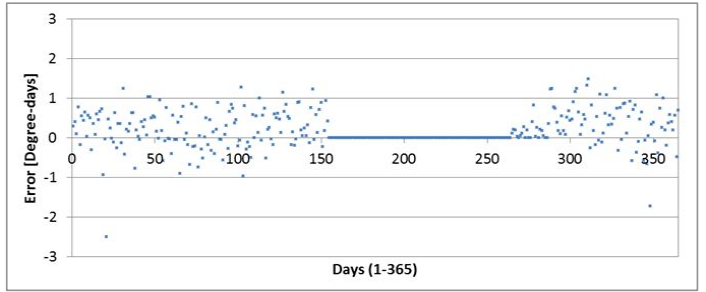

b. DD Error of Method 1 vs. Method 3

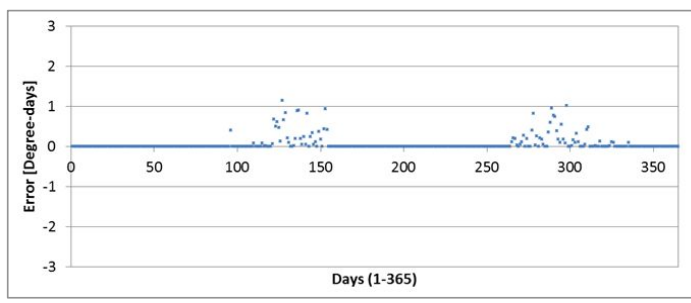

c. DD Error of Method 1 vs. Method 4

Fig. 3 Scatter plotting of DD calculation error relative to Method 1

계산방법상 Method 1과 4는 수학적으로 같 은 수식이나 도일에 포함시키는 기준이 시간별 외기온인지 일별 평균외기온인지의 차이만 가 지고 있다는 것을 알 수 있다. 따라서, Fig 3의 $\mathrm{c}$ 와 같이 기준온도와 비슷한 온도분포가 자주 나타나는 중간기에만 오차가 발생하는 것을 볼 수 있다. Method 2와 3도 역시 수학적으로 동 일한 방식이기 때문에 결과에 큰 차이는 없으 나 같은 현상으로 기준온도와 비슷한 외기온도 가 나타나는 중간기에서 도일 계산 포함여부의 차이를 보여주고 있는 점을 확인할 수 있다.

따라서, 도일법 계산방식의 차이는 이론적 으로는 의미가 있으나 도일법을 이용하여 실제
건물의 에너지 사용량을 예측하는데 있어서 보 다 중요한 것은, 기준온도를 설정하는 방식과 중간기에 발생한 도일을 어떻게 처리할지 결정 하는 것에 달려 있다는 것을 알 수 있다.

Table. 5 DDH Calculation result of each method for 30 years

\begin{tabular}{|c|c|c|c|c|c|}
\hline & Method1 & Method2 & Method3 & Method4 & Error* \\
\hline Jeju & 1665 & 1654 & 1639 & 1636 & $1.8 \%$ \\
\hline Jeju(A) & 1742 & 1748 & 1729 & 1708 & $1.9 \%$ \\
\hline Busan & 1946 & 1862 & 1841 & 1908 & $5.4 \%$ \\
\hline Masan & 1971 & 1917 & 1894 & 1930 & $3.9 \%$ \\
\hline Yeosu & 2067 & 2015 & 2000 & 2040 & $3.2 \%$ \\
\hline Wando & 2105 & 2042 & 2024 & 2071 & $3.8 \%$ \\
\hline Pohang & 2164 & 2097 & 2073 & 2121 & $4.2 \%$ \\
\hline Ulsan & 2193 & 2094 & 2060 & 2125 & $6.1 \%$ \\
\hline Kimhae(A) & 2226 & 2118 & 2081 & 2155 & $6.5 \%$ \\
\hline Mokpo & 2258 & 2152 & 2128 & 2213 & $5.7 \%$ \\
\hline Daegu & 2324 & 2225 & 2185 & 2251 & $5.9 \%$ \\
\hline Kwangju & 2375 & 2273 & 2238 & 2309 & $5.8 \%$ \\
\hline Kangneung & 2449 & 2387 & 2358 & 2397 & $3.7 \%$ \\
\hline Uljin & 2470 & 2404 & 2384 & 2431 & $3.5 \%$ \\
\hline Uleung & 2477 & 2400 & 2386 & 2453 & $3.7 \%$ \\
\hline Jinju & 2543 & 2392 & 2348 & 2450 & $7.7 \%$ \\
\hline Jeonju & 2555 & 2485 & 2448 & 2488 & $4.2 \%$ \\
\hline Kunsan & 2587 & 2554 & 2534 & 2552 & $2.0 \%$ \\
\hline Sokcho & 2637 & 2588 & 2570 & 2603 & $2.5 \%$ \\
\hline Seoul & 2760 & 2692 & 2665 & 2712 & $3.4 \%$ \\
\hline Daejeon & 2768 & 2684 & 2644 & 2687 & $4.5 \%$ \\
\hline Incheon & 2783 & 2713 & 2692 & 2746 & $3.3 \%$ \\
\hline Cheongju & 2809 & 2707 & 2670 & 2733 & $5.0 \%$ \\
\hline Seosan & 2885 & 2800 & 2770 & 2824 & $4.0 \%$ \\
\hline Andong & 2892 & 2803 & 2760 & 2809 & $4.6 \%$ \\
\hline Suwon & 2901 & 2846 & 2817 & 2845 & $2.9 \%$ \\
\hline Chupung & 2912 & 2829 & 2788 & 2831 & $4.3 \%$ \\
\hline Osan & 2976 & 2877 & 2838 & 2894 & $4.6 \%$ \\
\hline $\begin{array}{c}\text { Cheongju } \\
\text { (A) }\end{array}$ & 2990 & 2885 & 2838 & 2899 & $5.1 \%$ \\
\hline Wonju & 3049 & 2974 & 2932 & 2968 & $3.8 \%$ \\
\hline Kimpo(A) & 3062 & 3001 & 2966 & 2995 & $3.2 \%$ \\
\hline Chuncheon & 3188 & 3085 & 3042 & 3105 & $4.6 \%$ \\
\hline Youngwol & 3204 & 3129 & 3085 & 3114 & $3.7 \%$ \\
\hline Cheolwon & 3414 & 3357 & 3320 & 3336 & $2.7 \%$ \\
\hline $\begin{array}{c}\text { Daegwall } \\
\text { yeong }\end{array}$ & 4211 & 4151 & 4134 & 4168 & $1.8 \%$ \\
\hline
\end{tabular}




\section{3 도시별 30 년 평균 난방도일}

Table 5는 NCDC DB에서 선택된 국내 35 개 도시의 30 년 평균 난방도일 $\left(\theta_{b}=18^{\circ} \mathrm{C}\right)$ 의 각 방법별 계산결과를 보여주고 있다. Error*는 Method 1대비 다른 방법들의 절대오차 중 가 장 큰 오차를 보여주는 방법의 값을 의미하며 음영처리된 방법들이 각 도시에서 가장 큰 오 차를 가져오는 방법을 의미한다. 제주를 제외 한 모든 도시에서 미국의 방식인 Method 3과 의 오차가 가장 큰 것을 확인할 수 있다.

\section{5. 결 론}

$\mathrm{NCDC}$ 데이터를 기반으로 국내 주요도시의 냉난방도일을 다양한 방법을 통해 계산하고 그 결과를 비교하였다. 이러한 과정을 통해 얻 은 결론은 아래와 같다.

(1) $\mathrm{NCDC}$ 데이터는 보간법을 통해 매시각별 데이터로 변환되지만 매시각별 외기온의 비교에서 오차는 최대 $2.0 \%$ 이며, 난방도 일계산결과와의 비교에서는 최대 $0.7 \%$ 로 나타나 이 데이터의 활용성에 문제가 없 는 것으로 볼 수 있다.

(2) 매시각별 도일을 계산하는 Method 1은 수 학적으로 가장 정밀한 도일을 계산하나, 실제 건물들이 이론적으로 운전되지 않기 때문에 에너지예측의 정확성이 높다고 할 수는 없다. 다만, 다른 방법과 비교하여 가 장 높은 도일값을 가지게 된다.

(3) Method 1과 4, Method 2 와 3은 외기온이 $\theta_{b}$ 주위일 때에만 각각 오차를 보였으며, 이 오차는 중간기를 전후한 시기에 나타나 기 때문에 중간기 도일을 제외한다면 각 방법간 계산오차를 줄일 수 있다.

(4) Method 3이 일별 최고 및 최저 외기온도 의 평균값과 기준온도의 차이만으로 도일
을 계산하기 때문에 매 시각 차이를 고려 하는 Method 1대비 가장 큰 오차를 보이 는 것으로 나타났다.

(5) 각 계산방식들의 건물에너지 예측성능 평 가를 위한 실제 사용량과 비교연구가 필 요하며, 앞으로 보다 더 많은 도시를 대상 으로 그 결과를 발표할 예정이다.

\section{후 기}

본 연구는 한국에너지기술연구원의 연구비지원 (과제번호: B3-2433) 및 2012학년도 충북대학교 학 술연구지원사업의 연구비 지원으로 수행되었음.

\section{참 고 문 헌}

1. Myunghee Park, Haedong Kim, Kyoungsuk Song, Analysis of Urban Warming Phenomenon using Degree days in Major Korean Cities, Proceeding of the Korean Environmental Science Society Conference, Vol. 12(2), pp. 165 167, 2004

2. Jihae Kim. Seungjik Seo, The Demand Expectation of Heating \& Cooling Energy in Buildings According to Climate Warming, Journal of The Korean Solar Energy Society, Vol. 33 (3), pp. $67 \sim 74,2006$

3. Sangho Choi, Sangjun Lee, Sunghwan Cho. Energy Consumption Baseline Adjustment Using IWEC Weather Data \& Heating and Cooling Degree Days. Proceeding of The Society of Air-conditioning and Refrigeration Engineers of Korea Conference, pp 491 496, 2013

4. Youngeun Choi, Temporal and Spatial Variability of Heating and Cooling Degree-days in South Korea, 1973-2002, Journal of the Korean Geographical Society, Vol. 40, No. 5, pp. 584 593, 2005 
5. Sunghwan Cho, Seungsu Kim, Changyong Choi, Study on the Revision of HDD for 15 Main Cities of Korea, Journal of The Society of Air-conditioning and Refrigeration Engineers of Korea, Vol. 22 (7), pp 436 441, 2010

6. Mourshed, M., (2012), Relationship between annual mean temperature and degree-days, Energy and Buildings, Vol. 54, No. 11, pp. 418 $\sim 425$.

7. CIBSE (2006), Degree-days: theory and application, The Chartered Institution of Building Services Engineers, London, ISBN-10: 1-903287-76-6 